Revista Iberoamericana. $\quad$ Vol. LXII, Núm. 175, Abril-Junio 1996; 405-420

\title{
ALDEA ORAL/CIUDAD LETRADA: LA APROPIACIÓN VANGUARDISTA DE LO POPULAR EN AMÉRICA LATINA. EL CASO DE MIGUEL ÁNGEL ASTURIAS Y LAS LEYENDAS DE GUATEMALA
}

\author{
POR \\ MARIO ROBERTO MORALES
University of Pittsburgh
}

Cierta crítica posmoderna piensa las identidades subalternas como otredades en las que la representación - tanto mimética como política- de su sujeto se opone (y debe oponerse) a formas letradas de representación de esas identidades, y confiere estatuto de esencialistas a los operativos literarios y, en general estéticos, que los artistas y escritores "profesionales" han realizado incorporando las culturas subalternas a su discurso letrado. ${ }^{1}$ En este orden de ideas, todo lo relativo al sentido estético, ético y antropológico de los operativos vanguardistas de inclusión de las culturas populares a marcos artísticos experimentales potenciados por los ismos vanguardistas (tanto europeos como latinoamericanos), necesita ser revisado y revalorado a la luz (o a contraluz) del planteo posmoderno prosubalterno que contrapone, por ejemplo, el discurso testimonial al discurso vanguardista. ${ }^{2}$ No voy a analizar aquí la diferencia que existe entre la representación testimonial y la vanguardista en lo referido al pueblo, porque eso implicaría detenerse en la desconstrucción del testimonio. Pero he querido partir de esta aparente disyuntiva, que menosprecia e invalida el discurso vanguardista al reducirlo a una recreación pequeñoburguesa del discurso y la cultura campesinas e indígenas, porque sus implicaciones llevarían a que el vanguardismo y sus incorporaciones de lo popular hubiesen sido una especie de desviaciones culturales que seguramente debieran desecharse y borrarse de la historia cultural latinoamericana para ceder el paso a lo "auténticamente popular", léase: al discurso "verdadero" del explotado, marginal y subalterno, el cual quizá esté, al menos en parte, ubicado en la oralidad del testimonio, a pesar de la acción de sus mediadores letrados. En otras palabras y según esta lógica: la literatura debe ceder el paso a la oralidad transcrita al papel, en nombre de la "autenticidad" popular. En este ensayo me

\footnotetext{
${ }^{1}$ Ver, John Beverley, Against Literature (Minneapolis: University of Minnesota Press, 1993). En otro orden de cosas, las nociones de "letrado" y de "aldea oral" se remiten, por afirmación y por oposición respectivamente, a Ángel Rama, La ciudad letrada (Hanover: Ediciones del Norte, 1984).

2 "The 'popular' was either essentialized in petit bourgeois recreations of peasant and indigenous speech and culture (e.g., Salarrué in El Salvador, Asturias in Guatemala), or pawned off as mass culture (Fuentes, Puig, Sarduy) ... Like de Christian Base Communities, which are grassroots movements in which popular (i.e., exploited) sectors reread the gospel as the 'good news' of the coming of the Kingdom of God here on earth, the testimonial emphasizes a rereading of culture as lived history and a profesion of faith in the struggles of the oppressed". George Yúdice citado por John Beverley, ob. cit., 111.
} 
limitaré a hacer una defensa de la literatura como medio válido de formulación estética de identidades mestizas, híbridas, ${ }^{3} y$ en un próximo trabajo, abordaré el problema del testimonio y la oralidad como expresión de identidades populares (también híbridas), así como el de la diferencia de grado de autenticidad que existe - si es que existe - entre el testimonio y la novela. ${ }^{4}$ En el presente trabajo, los criterios de validez o invalidez estarán también remitidos al plano factual de la recepción textual y no únicamente reducidos a los ámbitos estéticos de su producción.

La vanguardia latinoamericana no es solamente una explosión de ismos y de proclamas y manifiestos que poco tienen que ver con el producto estético resultante, como en Europa. ${ }^{5}$ Es eso, pero también es un proceso cultural muy extendido en el tiempo que cumplió funciones distintas en América Latina que las que cumplió en Europa. ${ }^{6}$ Esta diferencia en las funciones del vanguardismo de uno y otro lado del mar es particularmente visible cuando consideramos el fenómeno vanguardista latinoamericano desde la perspectiva de sus apropiaciones de las culturas populares para lograr una síntesis estética transculturadora ${ }^{7}$ que amalgama oralidades, instantes de escritura automática, imaginerías remitidas a los ismos, formas verbales de textos

${ }^{3}$ La noción de hibridez e hibridación no implica reconocer la existencia de supuestas purezas de orden alguno. Más bien es una noción que sirve precisamente para desconstruir posiciones puristas, binarias y maniqueas, propias de ciertos fundamentalismos posmodernos que postulan la superioridad de las otredades marginales y subalternas frente a las centralidades canónicas. La posicionalidad híbrida propone mucho más ricas y complejas lecturas de estos problemas. Néstor García Canclini, Culturas híbridas (México: Grijalbo, 1989).

${ }^{4}$ Dice Beverley (op. cit., 76): "There is a crucial difference in power terms between having someone like Rigoberta Menchú tell the story of her people (and win a Nobel Prize herself) and having it told, however well, by someone like the Nobel Prize-winning Guatemalan novelist Miguel Angel Asturias". En el trabajo indicado se trataría de establecer en qué consiste exactamente esa diferencia de la que habla Beverley, y en que consiste ése "however well" de la versión asturianista.

5 Ver, Nelson Osorio, ed., Manifiestos, proclamas y polémicas de la vanguardia literaria en Hispanoamérica (Caracas: Biblioteca Ayacucho, 1988). También, Oscar Collazos, Recopilación de textos sobre los vanguardismos en la América Latina. Valoración múltiple (La Habana: Casa de las Américas, 1970).

6 "So far, the theory of the avant-garde has been treated at two levels: the level of the intention of the historical avant-garde movements and that of the description of the avant-gardiste work. The intention of the historical avant-garde movements was defined as the destruction of art as an institution set off from the praxis of life. The significance of this intention is not that art as an institution in bourgeois society was in fact destroyed and art thereby made a direct element in the praxis of life, but that the weight that art as an institution has in determining the real social efect of individual works became recognizable" Peter Bürger, Theory of the Avant-Garde (Minneapolis: University of Minnesota Press, 1984) 83. "The category art as an institution was not invented by the avant-garde movements (...) But it only became recognizable after the avant-garde movements had critized the autonomy status of art in developed bourgeois society". Ibidem Introduction, iii.

${ }^{7}$ Ángel Rama, Transculturación narrativa en América Latina (México: Siglo XXI, 1982) 3233. 
precolombinos que vienen de la oralidad, y creencias cristianas y de religiones anteriores al cristianismo en América. $^{8}$

En los años de la eclosión de los ismos europeos, varios escritores latinoamericanos que habrían de alcanzar fama internacional coincidían en París, en la "más famosa tertulia del mundo" ubicada en Montparnasse, la cual configuró el mito cultural parisino durante "los años locos", dando cabida a exiliados, bohemios y artistas de muchas nacionalidades. ${ }^{9}$ Entre los escritores que coincidieron en aquella tertulia puede mencionarse a James Joyce, Gertrude Stein, César Vallejo, Alejo Carpentier, Miguel Ángel Asturias, Luis Cardoza y Aragón, Alfonso Reyes, Arturo Uslar-Pietri, Pablo Picasso, Salvador Dalí, Luis Buñuel, y muchos otros. París fue el laboratorio en el que Asturias y Carpentier — para sólo hablar de los novelistas - no solamente encontraron la parte oscura y perdida de su identidadades latinoamericanas, sino donde experimentaron lasjunturas audaces que realizaban las vanguardias europeasy donde ejercieron las originalísimas apropiaciones que, con mentalidad vanguardista (ruptural e innovadora), los latinoamericanos hicieron de lo popular, lo primitivo, lo folklórico, lo oral y lo arqueológico de las culturas sedimentarias de las identidades americanas. ${ }^{10}$ Para el caso que nos interesa, allí fue donde Miguel Ángel Asturias entró en contacto con el surrealismo y con las mitologías mayas desde una perspectiva académica. Tanto el surrealismo (como corriente vanguardista) como el tono mágico de las leyendas (logrado mediante un uso ritual de la palabra), son dos ingredientes básicos de su vasto operativo verbal, al cual debe agregarse el insumo de la prosa de las crónicas españolas (y su tono exagerado), y el de la tradición literaria española (barroca) en general, así como el de la poética (preciosista)del Modernismo. Asturias refiere con palabras sencillas esta experiencia así:

En esta época frecuentábamos a algunos escritores muy preocupados del papel que jugaba la palabra en los textos literarios. Uno de estos autores, que fue gran amigo mío - lo digo con orgullo-, es Paul Eluard, el famoso poeta francés. Conocí también en esta época, aunque menos - muy de lejos, naturalmente- a James Joyce, conocí a Gertrude Stein, y en todos estos autores lo importante era la palabra: era lo que la palabra representaba dentro de la frase. (...) Recuerdo que Alejo Carpentier escribía entonces una novela de la que sólo algunos capítulos se publicaron, no sé si se publicó entera, en una revista que se llamó Imán, que se llamaba Ecue-Yamba-O. La novela empezaba más o menos así: "Ecueyambaó, retumban las tumbas en casa de Acué; yambaó, yambaó, en casa de Acué, retumban las tumbas, retumban las tumbas en casa de Acué". Es un poco el "¡Alumbra, lumbre de alumbre, Luzbel de piedralumbre!”. Esa cosa: nosotros teníamos la preocupación por el sonido de las palabras en esos momentos.

8 Jorge Schwartz, Las vanguardias latinoamericanas (Madrid: Ediciones Cátedra, 1991) 590599, para lo referido al Indigenismo. También, Gloria Videla de Rivero, Direcciones del vanguardismo hispanoamericano Tomo I (Mendoza: Universidad Nacional de Cuyo, 1990). Ver la síntesis final en página 295 y ss.

${ }^{9}$ Marc Cheymol, Miguel Angel Asturias dans le Paris des annés folles (Presses Universitaires de Grenoble 1987) 95 y ss.

${ }^{10}$ Este operativo vanguardista de apropiación de lo popular llega a un paroxismo creativo sin parangón con Macunaima, de Mario de Andrade, publicada en Brasil en 1928, al calor del Modernismo brasileño y de la ideología estética "antropofágica" de aquella vanguardia. 
Esto debemos unirlo también al movimiento surrealista que empezaba, que ya se estaba desarrollando en Francia; había llegado Tristán Tzara, había terminado un poco el dadaísmo, y comenzaba Breton y comenzaban los surrealistas a lanzar sus manifiestos y a impulsar la creación puramente mecánica. Nos entusiasmó a nosotros esta idea de podernos sentar a la máquina de escribir o frente a una cuartilla y empezar a escribir mecánicamente procurando la no intervención de la inteligencia; y entonces, con Arturo Uslar Pietri, un venezolano que escribía Las lanzas coloradas, hacíamos ejercicios de esta clase; pero los hacíamos con máquinas de escribir: Poníamos el papel y empezábamos a escribir en esa forma muchísimos textos que también se publicaron en esta revista que se llamó Imán. Estos textos, que al parecer eran disparatados, ya juzgados en cierta forma tenían una cierta unidad, caótica si se quiere, pero eran reveladores de un gran acervo del subconciente nuestro, de nuestra forma de ser y de pensar tal vez latinoamericana.

Ya en esta época empezamos tambien a estudiar, a formar, a escribir poemas en los cuales leyendo las palabras en un sentido significaban una cosa y juntando las palabras en donde terminaban con el principio de la siguiente palabra significaban otra cosa. Todo esto fue un gran trabajo de laboratorio.

Al mismo tiempo, yo estudiaba con el Profesor Raynaud "Mitos y leyendas de la América Maya"; quiere decir, que yo repartía mi tiempo entre los estudios éstos que realizaba en La Sorbona sobre los mitos indígenas y esta otra actividad lateral, que era una actividad que yo no me atrevo a llamar ni siquiera literaria, sino que era una actividad de gusto por la palabra, de gusto por la creación, por recordar, por conservar ..."

He citado en extenso a Asturias porque creo que en estas palabras suyas, grabadas primero y luego transcritas, sintetiza perfectamente el laboratorio que constituyó su estancia en París, su tertulia artística y su práctica escritural, que también incluía la hechura de artículos para el periódico El Imparcial de Guatemala. ${ }^{12}$ Sin duda, el surrealismo y sus posibilidades de expresión de imágenes inconcientes sirvióal pelo a Asturias para literaturizary ficcionalizar (usando la palabra y la frase, en su función poética, como elementos estructuradores del sentido del texto) las imágenes que a su vez le producía el estudio de las mitologías precolombinas, confrontadas con sus experiencias rurales de niñez y con las historias que le contaba su madre y su nana india. Por sí mismo, este estudio le confirió un sentido mucho más abarcador del componente maya de la identidad guatemalteca, que se movía (y se mueve aún) dentro de los límites estrechos de una nación inventada por cafetaleros criollos y ladinos ${ }^{13}$

1 Coloquio con Miguel Angel Asturias (Guatemala: Editorial Universitaria, 1968) 6-8. Este coloquio se llevó a cabo en la Rectoría de la Universidad de San Carlos de Guatemala en septiembre de 1966, con los profesores de literatura: Hugo Cerezo Dardón, Ricardo Estrada, Salvador Aguado Andreut, Guillermo Putzeys Alvarez y Francisco Albizúres Palma. Asturias había ya recibido recientemente el Premio Lenin de la Paz y recibiría al año siguiente el Premio Nobel de Literatura. Fue su última visita a Guatemala.

${ }^{12}$ Amos Segala, coord., París 1924-1933. Periodismo y creación literaria (Madrid: Edición Crítica, ALLCA, Colección Archivos, 1988).

${ }^{13}$ Como seguramente se sabe, el término ladino, en Guatemala, se usa para designar y diferenciar a cualquier guatemalteco considerado no-indio o no-maya, y tiene una carga más cultural que fenotípica. Las hibridaciones culturales, sin embargo, han relegado los conceptos excluyentes indio/ladino a un plano de abstracción referencial que en la práctica se difumina y hace porosas sus fronteras. 
que excluyeron al indio de su proyecto nacional. Asturias mismo fue un producto de este proyecto de nación racista y discriminatorio, según ha quedado evidenciado en su tristemente célebre tesis de abogado El problema social del indio (Guatemala, 1923), en la cual aparece evidente su mentalidad oligarquizada, ligada directamente con las ideologías políticas de la dominación dictatorial de losjunkers. ${ }^{14}$ Sin duda, París signficó para él un viraje ideológico radical. Este viraje ideológico, que implicó a la vezun abandono de la mentalidad oligárquica y una adhesión a la mentalidad capitalista modernizante, así como un operativo artístico literario de inclusión y fusión de las culturas subalternas mayas a una versión mestiza e híbrida de la guatemalidad, comienza a evidenciarse con Leyendas de Guatemala y forma parte de todo un movimiento vanguardista latinoamericano de apropiación, inclusión, resignificación y fusión de las culturas subalternas al proyecto moderno de nación que comenzaba a prefigurarse sobre todo en las mentalidades de intelectuales liberales. Nombres como Luis Palés Matos, en Puerto Rico, y Nicolás Guillén, en Cuba, para hablar de la inclusión vanguardista de la cultura de la negritud latinoamericana, deben ir unidos al de Miguel Ángel Asturias, Mario de Andrade y Alejo Carpentier, como exponentes vanguardistas de la apropiación recreadora de la cultura popular tradicional, vista como insumo básico para crear versiones estéticas de identidades mestizas para diversos países de América Latina, yendo más allá, por supuesto, de toda suerte de indigenismos asimilacionistas. ${ }^{15}$ En esta actitud residió el aporte revolucionario de la vanguardia latinoamericana, pues, como decía Mariátegui: "El sentido revolucionario de las escuelas o tendencias contemporáneas no está en la creación

\footnotetext{
${ }^{14} \mathrm{Si}$ queremos situar a Asturias y a todo el operativo vanguardista latinoamericano de inclusión de las culturas populares a su discurso letrado en relación con el momento político y económico que vivía entonces la América Latina, hay que enmarcarlo todo en la crisis de la dominación oligárquica y, sobre todo, en la transición de la via junker a la via farmer del capitalismo, según el esquema leninista desarrollado en El desarrollo del capitalismo en Rusia. Basándose sobre todo en El desarrollo del capitalismo en América Latina, de Agustín Cueva, Françoise Pérus analizó la narrativa del realismo social en este marco, en Historia y crítica literaria (La Habana: Casa de las Américas, 1982). Este es el marco de las vanguardias también, y aunque en el caso de Guatemala la transición se realizó sonoramente hasta la revolución de 1944, que luego fue truncada en 1954, ya el operativo de inclusión cultural popular de Asturias implicaba, en los años veinte, una mentalidad modernizante y ampliada respecto de la posible nación "moderna" guatemalteca, más soñada que real.

15 "While there is undoubtedly true that Carpentier's novel [Ecue-Yamba-O] on the culture of Cuba's Black population was more interesting for what it promised than for what it achieved, its project was similar to that of Macunaima and to Asturias's 'Legends of Guatemala'. Both he and Asturias were from small countries with large ethnic populations which made the question of a unified national identity more than usually problematical. Both were closely associated with the Surrealists in Paris in the 1920s; both knew of Joyce, both believed in the power of mith, metaphor, language and symbol, both were Freudian in orientation, Marxisant and revolutionary by instinct. They would each, from that moment, through the dark hibernatory age of the 1930s and 1940s - a fertile, global unconscious for both of them - gestate these ideas and in due course, around 1948, each would start to talk of 'magical realism' (Asturias) or 'the marvellous real' (Carpentier), whenever given the opportunity to do so. It was fitting that The Kingdom of this World and Men of Maize should have appeared in the same year, 1949" Gerald Martin, Journeys through the Labyrinth (London: Verso, 1989) 144-145.
} 
de una técnica nueva. No está tampoco en ladestrucción de una técnica vieja. Está en el repudio, en el deshaucio, en la befa del absoluto burgués". ${ }^{16}$ En la creación de una nueva sensibilidad, hubiera dicho Vallejo. Fernández Retamar elabora sobre esta idea de Mariátegui y dice que "Ya no se trataba de hablar generosamente de los negros (como la cubana Gertrudis Gómez de Avellaneda en su novela $S a b$, de 1841) o de los indios (como la peruana Clorinda Matto de Turner, en su novela Aves sin nido, de 1889), sino de hablar como negros, como indios, como los mestizos raciales y culturales que somos. Por supuesto, sería ingenuo atribuir solamente al traslado de las vanguardias europeas el reencuentro con las auténticas realidades de nuestro mundo. Pero indudablemente ellas contribuyeron a ese reencuentro, en la medida en que repudiaban el absoluto burgués, para insistir en las palabras de Mariátegui: es decir, en la medida en que eran verdaderas vanguardias, no ejemplos jactanciosos del espíritu decadente, o falsas vanguardias reabsorbidas por la sociedad que pretendían o pretenden repudiar; y, como verdaderas vanguardias, anunciaban o incluso asumían ya actitudes revolucionarias.

"En la América Latina existen, por supuesto, muchos casos, muchos matices: desde el de escritores entre dos mundos, como Huidobro (...) o escritores que involucionaron dramáticamente, hasta escritores que hacen plenamente visible ese 'papel catalizador' [de las vanguardias! (...): poetas como César Vallejo, Nicolás Guillén o Pablo Neruda; novelistas como Miguel Ángel Asturias o Alejo Carpentier". ${ }^{17}$

Fernández Retamar dice que se trataba de "hablar como negros, como indios, como los mestizos raciales y culturales que somos". Obviamente no se traba de hablar, sino de escribir. Pero no podemos decir: escribir como negros e indios, porque éstos no escribían, no tenían acceso a la "ciudad letrada" de que habla Ángel Rama, aunque los mestizos sí, y, por tanto, sí es lícito hablar de escribir como mestizos culturales. Y aquí hemos llegado al meollo de nuestro asunto: se trata de validar la escritura como locus de creación de un sujeto imaginario y una comunidad imaginaria mestizos, en el que la juntura de las diferencias hace precisamente la diferencia y constituye a este sujeto imaginario en el centro de los polos que en lo factual lo conforman, complementándose y excluyéndose simultáneamente. En esto reside la hazaña verbal de Asturias y su aporte revolucionario. No en hablar como indio y mucho menos en escribir como indio. Más bien su mérito consiste en escribir como mestizo. El mestizaje, entendido como hibridación cultural es, pues, el criterio-eje para examinar el operativo literario de Asturias, forjador no solamente de un sistema literario latinoamericano llamado "realismo mágico", ${ }^{18}$ sino prefigurador de la lucha político-cultural de laposmodernidad latinoamericana,

${ }^{16}$ Citado del ensayo "Arte, revolución y decandencia" (completo en Osorio, op. cit.) en Roberto Fernández Retamar, Para una teoría de la literatura latinoamericana (La Habana: Editorial Pueblo y Educación, 1984) 83.

17 Fernández Retamar, op. cit., 84.

${ }^{18}$ Ver, Alexis Márquez Rodríguez, "El surrealismo y su vinculación con el realismo mágico y lo real maravilloso", en Fernando Burgos, ed., Prosa hispánica de vanguardia (Madrid: Editorial Orígenes, 1986) 77-86. En este artículo, Márquez Rodríguez explica que fue Franz Roh, critico alemán quien usó por primera vez el término en 1925 para referirse "a cierta pintura posexpresionista que de algún modo se emparentaba conla pintura surrealista", y explica también que fue Uslar-Pietri quien primero usó el término aplicándolo a cierta cuentística latinoamericana. Aclara asimismo que cuando Carpentier habla de lo real maravilloso no se refiere "a fenómeno 
que consiste no en hacer valer la diferencia étnica y cultural per se, como señala Homi Bhabha, ${ }^{19}$ sino en amalgamar las diferencias en un sujeto situado más allá de los fundamentalismos que animan supuestas identidades puras, no negociables ni híbridas o mestizadas y transculturadas. Naturalmente, el operativo asturianista es, además de letrado, un operativo ladino, y no maya ni oral: es la apropiación de lo marginal y subalterno maya desde una posicionalidad central para expresar una identidad mestiza e híbrida. El operativo de Rigoberta Menchú es inverso: es la apropiación del código dominante y central para expresar una identidad híbrida y mestiza desde una posicionalidad maya y subalterna. Es con estos criterios que deberemos examinar algunos núcleos verbales constitutivos de Leyendas de Guatemala (el testimonio de Menchú queda pendiente), texto fundacional de una latinoamericanidad mestiza imaginada, escrito en $1928,{ }^{20}$ cuando Mariátegui escribía sus Siete ensayos ..., cuando Mario de Andrade publicaba su extraordinario Macunaima, y publicado por primera vez en la primavera de 1930 en Madrid. ${ }^{21}$

Leyendas de Guatemala es un texto seminal de la cultura americana que misteriosamente ha sido ignorado por la crítica. ${ }^{22}$ Cardoza y Aragón se refiere a él como "obra con sabor de leyenda precolombina, colonial y surrealista". Y dice algo sobre su autor que deberá interesarnos a la hora de analizar otras obras suyas: "Ahí no estaba el germen sino ya definida su imaginación y su sensibilidad". ${ }^{23}$ Leyendas de Guatemala es una obra de juventud y, a la vez, de hallazgo fecundante, porque la audaz hibridación que Asturias realiza entre metáfora surrealista, imágen poética colonial-barroca, imaginería poética precolombina y textualidad modernista es asombrosa, empezando por la estructura misma del libro, el cual originalmente se publicó sin los textos titulados "Cuculcán" y "Los brujos de la tormenta primaveral”, que fueron agregados por Asturias en la edición argentina de 1948. ${ }^{24}$

Después de la carta de Paul Valéry a Francis de Miomandre, traductor al francés de las Leyendas, el texto abre con una especie de exordio que se titula "Guatemala", y que se

alguno vinculado con la creación artística o literaria" sino a "la existencia de una realidad que es per se maravillosa, y que él opone a lo maravilloso artificial ..." Luego habla de Carlos Fuentes, García Márquez y Roa Bastos como exponentes del realismo mágico y no menciona para nada a Asturias. Obviamente, resulta mucho más loable, para la dignidad de este critico, pensar en mala intención que en ignorancia.

19 Homi Bhabha, "Dissemi-Nation", en H. Bhabha, ed., Nation and Narration (London: Routledge, 1990) 312-313.

20 "Les Légendes auraient done été comencées des 1925, peu des temps apres l'arrivée d'Asturias a Paris. Certaines étaient en tout cas écrites en 1928, puisque lors de sa tournée de conférences au Guatemala, apres le congres de Presse Latine a Cuba, l'auteur en présenta quelques-unes: “Un soir, il réunit les intellectuels qui écouterént religieusement la lecture de quelques légendes du Guatemala, qui font partie d'un volume qu'Asturias publiera prochainement en Europe"' Alfredo Balsells Rivera, "Una figura nuestra: la barba de Miguel Angel", El Imparcial (30 juin 1928). En Marc Cheymol, op. cit., 165.

${ }^{21}$ Ibidem.

22 "Asturias's deceptively titled 'Legends of Guatemala' (1930), still virtually unstudied to the present day, is the first major anthropological contribution to Spanish American Literature". Gerald Martin op. cit., 146.

${ }^{23}$ Luis Cardoza y Aragón, Miguel Angel Asturias casi novela (México: ERA, 1991) 15.

${ }^{24}$ René Prieto, Miguel Angel Asturias's Archeology of Return (Cambridge: Cambridge University Press 1993) 66-67. 
estructura como una especie de mural antropológico-cultural, desplegando un relato en el que pasado y presente se con-funden en una atmósfera nostálgica y evocadora. El mural va desde los decires de cierto sentido común popular de capas medias rurales y ladinas, expresado en hábitos de viejos que tienen güegüecho, hanvisto espantos, andarines y aparecidos, cuentan milagros y cierran la puerta cuando pasan los húngaros: esos que roban niños, comen caballo, hablan con el diablo y huyen de Dios, ${ }^{25}$ hasta recreaciones del imaginario maya precolombino, pasando por la poética y la patriótica colonial española y criolla.

Este sentido común popular, clasemediero, rural y ladino, implica un imaginario colectivo poblado de temores y fantasías que a la vez implican la existencia "vivida" (como ideología) de un mundo mágico paralelo al mundo real, y una posicionalidad del sujeto que vive ese sentido común ubicada en la encrucijada de esos dos mundos: el del capitalismo subdesarrollado y el de la magia colonial, híbrida y mestiza. ¿Por qué del capitalismo subdesarrollado? Porque estos viejos descritos arriba, son ubicados por el autor en su situacionalidad económica cuando dice: En el apeadero, donde se encuentran la calle y el camino, está la primera tienda. Sus dueños son viejos, tienen güegüecho ...., etc. (11). Notemos que la tienda de estos viejos portadores del sentido común está ubicada en un apeadero que a la vez está situado donde se encuentran la calle y el camino: es decir, en el comienzo del casco urbano de una población rodeada por el monte y el final de la vía que la comunica con el exterior. Encrucijada entre el mundo urbano y rural, la tienda, emporio del comercio subdesarrollado, se sitúa como uno de los espacios económicos que hacen posible las hibridaciones culturales que pueblan el sentido común y el imaginario colectivo mestizo y que se desarrollan en este mural cultural, el cual inicia, además, con una metáfora del subdesarrollo a la vez colorida y dolorosa: "La carreta llega al pueblo rodando un paso hoy y otro mañana" (11).

El sujeto mágico con el que Asturias abre su libro es, pues, un sujeto ladino, mestizo, como su imaginario. El mural sigue desarrollándose y el autor evoca desde una perspectiva arqueológica el mundo maya precolombino, al cual ubica en las brumosidades del sueñoy del inconsciente por medio de imaginerías surrealistas:

El Cuco de los Sueños hace ver una ciudad muy grande - pensamiento claro que todos llevamos dentro-, cien veces más grande que esta ciudad de casas pintaditas en la Rosca de San Blas. Es una ciudad formada de ciudades enterradas, superpuestas, como los pisos de una casa de altos. Piso sobre piso. Ciudad sobre ciudad (12).

Esta visión de superposiciones expresa a la vez la integralidad y la separatidad de los componentes maya y occidental de Guatemala, ${ }^{26}$ y a la vez propone la existencia amalgamada

\footnotetext{
${ }^{25}$ Miguel Ángel Asturias, Obras escogidas, tomo I (Madrid: Aguilar, 1955). A no ser que se indique lo contrario, las citas de Asturias se refieren a esta edición y sólo se indicara la página al final de cada una.

26 "Rather than amalgamating Indian and Western elements into a mestizo culture (like de one Arguedas proposes), Asturias goes to great lenghts to portray de former as a wholly separate, but no less integral, part of his country's cultural patrimony" René Prieto, op. cit., 39. Después veremos cómo Asturias también propone un mestizaje cultural a su manera.
} 
de la ciudad letrada, la ciudad planificada y ordenada, y lo que podríamos llamar la aldea oral, porque continúa diciendo:

¡Libro de estampas viejas, empastado en piedra con páginas de oro de Indias, de pergaminos españoles y de papel republicano! ¡Cofre que encierra las figuras heladas de una quimera muerta, el oro de las minas y el tesoro de los cabellos blancos de la luna guardados en sortijas de plata! Dentro de esta ciudad de altos se conservan intactas las ciudades antiguas. Por las escaleras suben imágenes de sueño sin dejar huella, sin hacer ruido. De puerta en puerta van cambiando los siglos. En la luz de las ventanas parpadean las sombras. Los fantasmas son las palabras de la eternidad. El Cuco de los sueños va hilando los cuentos (13).

Las ciudades sobrepuestas son vistas como libro de estampas viejas y como cofre que encierra la memoria perdida de las ciudades mayas que se encuentran intactas en el sueño, en el inconciente, en la imaginación de quien las busca para constituirse como sujeto híbrido y mestizo y otorgarse así una identidad que incluya el componente negado en el proyecto de nación oficial de perfiles liberales. Hibridación de ciudad letrada y aldea oral, este párrafo, confeccionado además con imaginerías evidentemente surrealistas, resulta emblemático de la propuesta antropológica de Asturias: Guatemala es mestiza porque es híbrida y el componente maya ocupa un lugar central en el imaginario de la identidad ladina. No olvidemos nunca que la propuesta de Asturias es ladina, y que no podía no haberlo sido.

El componente europeo no se encuentra menos destacado en este texto, ni mucho menos el barroquismo que luego Carpentier habría de postular como expresión americana, cuando Asturias nos dice:

Estamos en el templo de San Francisco. Se alcanzan a ver la reja que cierra el altar de la Virgen de Loreto, los pavimentos de azulejos de Génova, las colgaduras de Damasco, los tafetanes de Granada y los terciopelos carmesí y de brocado. ¡Silencio! Aquí se han podrido más de tres obispos y las ratas arrastran malos pensamientos (17).

Igualmente notamos aquí un claro anticlericalismo liberal en la última frase, el cual sin embargo, no rebasa un ámbito católico de perfiles patéticos y llenos de temores apocalípticos propios del cristianismo inquisitorial que arriba a América con los conquistadores: "Por las altas ventanas entra furtivamente el oro de la luna. Media luz. Las candelas sin llamas y la Virgen sin ojos en la sombra"(17). Esta Virgen sin ojos es a la vezel silencio de las divinidades y el temor a las imágenes sacras que hacen al sentido común popular invocar a las fuerzas paganas de esa otredad religiosa que se entrecruza con la fe cristiana en América Latina.

En el texto que sigue, titulado "Ahora que me acuerdo", Asturias inserta citas largas de la versión al español del Popol Vuh que el Abate Gonzalez de Mendoza y un poco el mismo Asturias realizaron de la versión francesa de Georges Raynaud, ${ }^{27}$ y empieza a desplegar

27 "Ahora estamos al corriente de que Asturias no tradujo el Popol Vuh. Lo tradujo José María González de Mendoza (1893-1967), Abate de Mendoza. (...) Si recojo esta información, que conocí sorprendido, se debe a que se trata de una aclaración pertinente, dada la categoría de los protagonistas: tanto González de Mendoza como Francisco Monterde fueron muy respetados por su responsabilidad intelectual y honradez absolutas" Cardoza y Aragón, op. cit., 15-16. A 
recursos onomatopéyicos y juegos de palabras que, contrariamente a lo que se suele creer, no constituyen enteramente una creación de Asturias sino que vienen de una práctica popular, ladina y maya, de Guatemala, muy común y presente siempre en el humor local. Asimismo, escribe ya en la clave de los textos precolombinos, cuestión que hace de los contenidos algo que es casi imposible de penetrar más allá de la belleza formal, barroca y surrealista del lenguaje:

Bailando como loco topé el camino negro donde la sombra dice: “¡Camino rey es éste y quien lo siga el rey será!" Allí vide a mi espalda el camino verde, a mi derecha el rojo y a mi izquierda el blanco. Cuatro caminos se cruzan antes de Xibalbá (24).

Paradójicamente, muchas de las formas "incorrectas" de hablar el castellano que se observan en las hablas populares tanto ladinas como mayas, provienen del castellano peninsular de la época de la Colonia, y Asturias a menudo las usa para expresar supuestas realidades mágicas precolombinas (Allivide a mi espalda) desde una perspectiva ladina. Las traducciones de los textos precolombinos en los que se usa el "vosotros" para expresar alcurnia y nobleza maya en los diálogos o las invocaciones, etc., son igualmente paradójicas, y pienso ahora en la traducción al castellano que Luis Cardoza y Aragón hizo de la versión francesa de Georges Raynaud del Rabinal Achi, en la que se echa mano del mismo recurso a todo lo largo del texto. ${ }^{28}$ Las hibridaciones lingüísticas, propias de la ciudad letrada sirven, pues, para expresar-de nuevo, paradójicamente-a la aldea oral. Y esta es la manera como la ladinidad letrada incluye la otredad maya como componente básico de su identidad: se la apropia de la mejor manera que puede, y la asume de la única manera que sabe.

El operativo de hibridación asturianista consiste, pues, en su apropiación creadora no sólo de las culturas precolombinas y sus claves desde los ismos vanguardistas. Sino, también, en su apropiación de los ismos vanguardistas desde su posicionalidad de guatemalteco ladino, mestizo, letrado, en la encrucijada histórica que lo compele a integrar la otredad negada en el proyecto incompleto de nación guatemalteco, y a integrar esa otredad a su propia identidad ladina que también había negado, explícitamente además, esa otredad (en su tesis de abogado). Asturias no es, quiero argumentar, un escritor vanguardista que se apropia de lo popular, lo folklórico, lo precolombino nada más. Es un escritor que se apropia de eso y también de las vanguardias. Las vanguardias son, en él, una apropiación antropofágica, en el mejor sentido del término, tanto como lo son las culturas tradicionales de Guatemala. En eso radica la originalidad revolucionaria de la obra asturianista desde el punto de vista de su producción. Desde el punto de vista de su recepción, es interesante notar que, en Guatemala, no existe nadie a quien "no le guste" Asturias, y sus lectores se reconocen en él y reconocen en su versión

propósito de este conflicto, ver de Luis Cardoza y Aragón, El Río novelas de caballería (México: FCE, 1986) 207-208; también, René Prieto op. cit., 31-32, quien dice: "It is difficult to ascertain whether a declaration made [by Monterde] many years after the translations were completed [1927] is truthfull or prompted by a soured friendship". Antes, Prieto informa que González de Mendoza y Asturias tradujeron en 1928 los Anales de los Xahil.

${ }^{28}$ No hay que olvidar nunca que Asturias leyó el Popol Vuh y otros documentos mayas por primera vez en francés, y que igualmente Cardoza leyó el Rabinal Achí por primera vez en francés, pues no existían traducciones al español de esos textos, anteriores a las que hicieron ellos. 
a una Guatemala propia, soñada y vivida, aunque irreal. Pero el estudio de la recepción de la obra de Asturias merece un ensayo aparte. Adentrémonos por ahora en las hibridaciones que estructuran las leyendas para redondear su propuesta híbrida de una identidad mestiza desde la ladinidad letrada, desde una forma de ser de la latinoamericanidad letrada.

$\mathrm{El}$ argumento de las leyendas se reduce, en la versión asturianista, a unas cuantas líneas. Lo demás son palabras, juegos de palabras, ríos de palabras, ambientes, atmósferas y ámbitos hechos de palabras, porque son las palabras los instrumentos que Asturias usa para mimetizarse y escribir desde lo que él siente como la otredad maya y popular, que sale al encuentro de la centralidad ladina y visceversa. Esto es particularmente observable en "Los brujos de la tormenta primaveral" y "Cuculcán", que son los textos más "mayas" de las Leyendas de Guatemalay que se sitúan mucho más allá de los indigenismos latinoamericanos, mediante un operativo lingüístico mimético sin precedentes en la vanguardiay en la tradición literarias. ${ }^{29}$

En la "Leyenda del Volcán”, Asturias caracteriza aun personaje mediante una imaginería explícitamente surrealista con combinaciones háblicas populares ladinas:

Uno de los del viento volvió a ver y sus compañeros le llamaron Nido.

Monte en un Ave era el recuerdo de su madre y su padre, bestia color de agua llovida que mataron en el mar para ganar la tierra, de pupilas doradas que guardaban al fondo dos crucesitas negras, olorosas a pescado, femenina como dedo de meñique (30).

En la "Leyenda del Cadejo", el surrealismo es empleado para expresar veneraciones católicas mediante un barroquismo que recuerda la tradición literaria española:

Las monjas - rosales ambulantes- cortábanse las rosas unas a otras para adornar los altares de la Virgen, y de las rosas brotaba el mes de mayo, telaraña de aromas en la que Nuestra Señora caía prisionera temblando como una mosca de luz (38).

En la "Leyenda de la Tatuana", el elemento modernista puede observarse claramente cuando escribe:

29 "The originality of his innovation cannot be ignored: He is not merely defending the Indians, he is writing about them from their own perspective. [Claro que esta "perspectiva de ellos" implica un travestimiento literario y, por tanto, una apropiación artística de Asturias]. As Carlos Fuentes once declared, "Asturias deja de tratar al indio ... de una manera documental, para penetrar la raíz mítica, la raíz mágica, a través del lenguaje que hablan estos seres [De nuevo, esta forma de "hablar" es un artificio mimético de Asturias y no es que sea propio de "estos seres"]. A través de su lenguaje, Asturias los salva de la anonimia impuesta por la historia" ("Situación del escritor", 19-20). [Aunque la visión de Fuentes es paternalista porque todavía ve en el operativo asturianista un salvamento del indio, y aunque todavía confunde literatura con "realidad", es rescatable el criterio de que Asturias "deja de tratar al indio ... de una manera documental", y lo trata linguísticamente"] René Prieto, op. cit,. 41. Las notas entre paréntesis son mías. Pero Prieto va má allá y dice: "Asturias does not suggest (as do Ciro Alegría and José María Arguedas) that Indians have to understand and absorb the beliefs and thougth structures of the dominant class. Instead, his aim is to show the wealth and validity of the Indian's owns beliefs and thought structures" Ibidem. Pero no para proponerlos como alternativas a las estructuras de pensamiento occidentales, ladinas, sino como componentes de una identidad mestiza, híbrida. 
-Allá - continuaba con la cara mitad bañada por el sol— todo será tuyo. ¡Eres una joya, y yo soy el Mercader de Joyas sin precio! ¡Vales un pedacito de alma que no cambié por un lago de esmeraldas! ... (44).

Pero en medio de estos arrebatos darianos llenos de joyas y lagos de esmeraldas, Asturias introduce a veces vocablos que nos ubican en su contemporaneidad moderna: "Y los treinta servidores montados llegaban a la retina como figuras de un sueño"(45). Sin duda, el vocablo "retina" no pudo haber estado en el léxico de los personajes que Asturias esboza y probablemente ni siquiera en el de las capas medias ladinas entre las que circulaban las leyendas. Lo mismo ocurre con la noción de fotografía y fotógrafo en el siguiente pasaje: “... y los primeros relámpagos iluminaron el paisaje, como los fogonazos de un fotógrafo loco que tomase instantáneas de tormenta" (45).

En la "Leyenda del Sombrerón" se hacen patentes las claves de las crónicas españolas:

Y era de ver y era de oír y de saber los discursos en que por días y noches se enredaban los más eruditos, trayendo a tal ocurrencia citas de textos sagrados, los más raros y refundidos.

Y era de ver y era de oír y de saber la plácida tertulia de los poetas, el dulce arrebato de los músicos y la inaplazable labor de los pintores, todos entregados a construir mundos sobrenaturales con los recados y privilegios del arte (48-49).

Y es de ver cómo Asturias hibridiza sus insumos con los recursos vanguardistas para lograr esas atmósferas que calan el inconsciente, apelan a él para que se identifique con una versión de síntesis de la cultura y la identidad mestizas, híbridas. Y es de oír también cómo Asturias asume una voz de narrador oral para contar algunos pasajes, cuestión que nos recuerda la dedicatoria de su libro (“A mi madre, que me contaba cuentos”):

El religioso, que leía la Anunciación de Nuestra Señora en un libro de antes, vio entrar el cuerpecito extraño, no sin turbarse, entrar y rebotar con agilidad midiendo piso y pared, pared y piso, hasta perder el impulso y rodar a sus pies, como pajarito muerto (50).

La ciudad letrada dice a la aldea oral y ésta contribuye a que aquélla se diga a sí misma como síntesis mestiza e híbrida.

En esta misma leyenda, irrumpe de nuevo el léxico de la contemporaneidad modernamediante el vocablo "dentífrico"-en la confección de imaginerías surrealistas cuando dice:

Fruncía las cejas - brochas en las. que la atención riega dentífrico invisible - y tras vanos temores reconciliábase con la pelotita, digna de él y de toda alma justa, por su afán elástico de levantarse al cielo (51).

En la "Leyenda del Tesoro del Lugar Florido" hay una descripción de un mercado precolombino con una técnica enumerativa que me hace recordar la versión que de los mercados de su contemporaneidad'moderna da Cardoza y Aragón en Guatemala las líneas de su mano. La imaginación de Asturias, basada en el conocimiento libresco (no es posible otro) de lo 
precolombino, estuvo sin duda mediado por su propia visión de los mercados guatemaltecos de su tiempo:

Y ya fue noche de mercado. El lago se cubrió de luces. Iban y venían las barcas de los comerciantes, alumbradas como estrellas. Barcas de vendedores de frutas. Barcas de vendedores de vestidos y calzas. Barcas de vendedores de jadeítas, esmeraldas, perlas, polvo de oro, cálamos de pluma llenos de aguas aromáticas, brazaletes de caña blanca. Barcas de vendedores de miel ..., etc. (54-55).

En esta cita se evidencia otro rasgo fundamental de la versión asturianista de lo americano: la visualidad barroca, que a su vez evidencia la influencia enorme del cine sobre su imaginario.

En "Los Brujos de la Tormenta Primaveral", Asturias inventa un lenguaje "maya" absolutamente mágico, extraído no sólo de las cadencias y los ritmos y reiteraciones de los textos precolombinos, sino también de la imaginería surrealista de la Biblia judeo-cristiana, presentes en textos como el Génesis y el Apocalipsis. Porque si hay un arquetipo del verbo surrealista, ése es el Apocalipsis, de Juan. Asturias abre el texto con un discurso genésico pero también apocalíptico, que nos hace vivir la ilusión de que estamos frente a un discurso maya (whatever that may be), sea lo que eso fuere en alguna realidad, pasada o presente:

Más allá de los peces el mar se quedó solo. Las raíces habían asistido al entierro de los cometas en la planicie inmensa de lo que ya no tiene sangre, y estaban fatigadas y sin sueño. Imposible prever el asalto. Evitar el asalto. Cayendo las hojas y brincando los peces. Se acortó el ritmo de la respiración vegetal y se enfrió la savia al entrar en contacto con la sangre helada de los asaltantes elásticos.

Un río de pájaros desembocaba en cada fruta. Los peces amanecieron en la mirada de las ramas luminosas. Las raíces seguían despiertas bajo la tierra (65).

Luego combina recursos popolvúhicos con formas coloquiales ladinas, como cuando dice:

Chorro de Horizontes se desnudó de sus atavíos de guerra para vestir su sexo y por nueve días, antes de abultar la luna, estuvo tomando caldo de nueve gallinas blancas día a día, hasta sentirse perfecto (73).

Los mitos de origen están tratados aquí con una solemnidad que solamente es rota de vez en cuando por un humor soterrado, como el que se observa en el párrafo anterior: un caldo, en lenguaje coloquial ladino, significa un acto sexual; en tal sentido, "vestir su sexo" implica vestirlo con el sexo opuesto; y la alusión a las gallinas refiere obviamente a las mujeres. Por lo demás, la situación está remitida a prácticas tántricas comunes entre la nobleza maya (patriarcal), aunque enfocada desde una perspectiva ladina notoriamente machista. Es sorprendente ver cómo este hecho emparenta a Leyendas de Guatemala con Macunaíma, aunque el énfasis paródico de los mitos de origen en ésta es un factor estructurante que no opera en las Leyendas. ${ }^{30}$

30 "Así, el uso que hace Mario de Andrade de lo primitivo (es decir, del material tribal) ocurre dentro de un contexto de fluidez y migración de formas estéticas y, en este sentido, no es una continuación 
El tono de los mitos de origen aparece reiteradamente en esta pieza, por ejemplo en pasajes como este: "Y así fue como hombres y mujeres nacidos de menguante, poblaron la Ciudad de la Diosa Invisible de las Palomas de la Ausencia" (77), en los cuales la incorporación de lo primtivo y prerracional mediante una poesía pura surrealista, emparenta a Asturias con las vanguardias europeas, que también sondearon las posibilidades de las culturas primitivas, como ocurrió con Picasso y el cubismo respecto de ciertas expresiones plásticas africanas. Sin embargo, en las vanguardias europeas, la búsqueda de lo prerracional era la búsqueda de una expresión no mediada por las represiones de la civilización burguesa (puesta en crisis por la Segunda Guerra Mundial), y en las vanguardias latinoamericanas esa búsqueda tiene que ver más con la sentidanecesidad de inclusión de los componentes étnicos y culturales negados en los proyectos liberales y conservadores de nación, y con lanecesidad de completar también los perfiles de la identidad hegemónica, ligada a lo nacional sí, pero ya trabajando en la ampliación -vía inclusión-de la nación inconclusa.

La reelaboración barroca y surreal de estos mitos precolombinos que Asurias realiza en este texto mediante recursos háblicos de su niñezy de su contemporaneidad, constituye, junto al resto de Leyendas de Guatemala, las "Fantomimas" ("Rayito de Estrella", 1929; "Emulo Lipolidón”, 1935; “Alclasán”, 1940, y “El rey de la altanería”, 1948), Mulata de tal, Tres de cuatro soles y El arbol de la cruz, ejemplo esencial de su poética híbrida e ideológicamente mestiza, y, en el decir de Gerald Martin, "libros vanguardistas-linguísticos-antropológicos, precursores de la obra 'neobarroca' de escritores como Sarduy ...".31

Finalmente, "Cuculcán" es un híbrido muy intersante, mezcla de tragicomedia con elementos circenses, y parodia de las divinidades precolombinas con lenguajes surrealistas remitidos a la imaginería de los textos mayas. Interesante sería estudiar su estructura en relación a la estructura del Rabinal Achi, aunque se puede adelantar que la elaboración de Asturias dista mucho de la de esta pieza de teatro precolombino, totalmente solemne y destinada a cumplir funciones sociales completamente distintas de las de las cumplidas por las vanguardias latinoamericanas, consistentes en hacer recaer sobre la palabra todo el peso de la creación literaria, y en impulsar la ideología nacionalista moderna de incluir los márgenes en el centro de la nación, la nacionalidad y la identidad latinoamericanas, visto todo como una forma de compromiso. ${ }^{32}$

del folclor por otros medios. Más bien, corresponde al interés hacia el arte tribal, característico de las vanguardias de principios del siglo XX". Esta cita del libro de William Rowe y Vivian Schelling, Memoria y modernidad (México: Grijalbo, 1993) 242, es perfectamente aplicable a Asturias y, sin duda, Leyendas de Guatemala es uno de los textos en los que "las culturas populares cumplen una función estructuradora, al alterar formas heredadas de cultura elevada, como la novela, mediante el uso de formas estéticas populares" Ibidem, 243. En el caso de Asturias, "su método ha consistido en traer las prácticas culturales de grupos sociales subalternos al centro de la narrativa ...", (...) "Los autores más notables en este muy amplio campo incluyen al guatemalteco Miguel Angel Asturias y al brasileño Joao Guimaraes Rosa" Ibid., 251-252.

${ }^{31}$ Gerald Martin, "Asturias y Sarduy: de cuando son los cantantes (Nota crítica)", inédito aún en el otoño de 1995.

32 “... Miguel Angel Asturias's Leyendas de Guatemala and El señor presidente (...) marked the beginnings of a literary éngagement with Indian culture" John Beverley and Marc Zimmermann, Literature and Politics in the Central American Revolutions (University of Texas Press, 1990) 43. 
Naturalmente, el operativo asturianista es, como hemos dicho, un operativo letrado y ladino, opuesto a lo que sería un operativo oral y maya, como el de Rigoberta Menchú. Cada uno se acerca a la nacionalidad mestiza guatemalteca desde posicionalidades diferentes, ambas populares, una letrada y la otra oral, si admitimos que lo popular a estas alturas solamente puede determinarse a partir justamente de posicionalidades y no de esencialidades ningunas. Asturias nunca dejó de ser un letrado que, en última instancia, optó siempre por la "civilización" y no por la "barbarie", según el axioma sarmientino. La prueba está en sus propias palabras cuando un joven escritor de entonces le pregunta en 1966: “¿Qué nos podría usted decir a nosotros, que estamos sin guía para poder continuar esa tradición que hay que continuarla en las letras hispanoamericanas?”, y Asturias le responde: “... creo yo, mi querido amigo, que tienen guíasy muy grandes. Yo creo que un Facundo de Sarmiento, si lo revisamos y lo estudiamos, nos permite un estudio profundo sobre nuestras posibilidades políticas, en la lucha que nos presenta Facundo entre la barbarie y la civilización. (...) Los grandes, José Martí, los grandes de América deben ser nuestros guías". ${ }^{33}$

Interpretando estas palabras de Asturias vis á vis su obra literaria, pareciera que su inclusión de lo maya en lo nacional presupone la necesidad de un ingreso de mayas y ladinos (juntos) en la "civilización", y no una negación de ese derecho a los mayas mediante un asimilacionismo indigenista ladino, que es lo que expresa el término mestizaje entendido en forma tradicional. Esto es, de suyo, revolucionario en los tiempos de Asturias, y solamente remitible al pensamiento de Mariátegui. Todo, claro, desde una perspectiva letrada, como lo era también la de Mariátegui. Si es posible interpretar así la juntura brusca que Asturias hace de Sarmiento y de Martí, habría prefigurado las reivindicaciones de los mayas de fines del siglo XX, que plantean su ingreso en la (pos)modernidad como mayas y sin pasar por el filtro negatorio de la ladinización.

Si insistimos en que el código letrado de Asturias es "inadecuado" para representar miméticamente al subalterno maya porque el código maya es distinto (y desconocido) por subalterno, esta inadecuación de su código nos remitiría a juzgar como válida o no su versión de la subalternidad, exclusivamente desde las coordenadas estético-vanguardistas, y punto. Desde esta perspectiva, probablemente no haya habido una versión de inclusión de la marginalidad subalterna latinoamericana más democrática que la de Asturias en la ciudad letrada. Y eso, si bien no bastaba, ya era mucho. Bastante, diría yo.

En el plano factual de la recepción de la obra de Asturias, no existe mejor argumento para validar su representación de la subalternidad maya de Guatemala, que la constante recurrencia generalizada a sus iconos para expresar la nacionalidad (mutilada y todo), también de parte de un escritor indio, Luis de Lión (con i), quien al escribir su novela El tiempo principia en Xibalbá y ofrecer una versión del indio alternativa a la de Asturias, porque se trató de una versión crítica y autocrítica, no renuncia en ningún momento al legado asturianista, que le sirvió al pelo para expresar la mayidad contemporánea (anterior al holocausto contrainsurgente de los años ochenta). Hay otros escritores mayas de hoy día que reclaman autenticidad frente a Asturias, y habrá que confrontar su obra con la de él y con la de Luis de Lión, porque si por un lado Asturias inventa a un indio desde la ladinidad y Luis de Lión expresa a un indio desde la indianidad, los escritores de hoy día expresan una realidad maya que tiene que ver más con

${ }^{33}$ Coloquio con Miguel Angel Asturias, citado, 34-35. 
la posmodernidad de las artesanías adecuadas al gusto de la demanda internacional, que con la afirmación de una otredad divorciada de hibridaciones. Sin embargo, y aquí radica lo curioso de este asunto, los escritores e intelectuales mayas o indios posmodernos - tanto en la poesía (Humberto Ak'abal) como en la ciencia social(Demetrio Cojtí)_reclaman para sus versiones y planteamientos la completa otredad, aun cuando su producción está mediada por el mercado y sus ambiciones dirigidas hacia su ingreso en la posmodernidad globalizada. Apelando pues, a una pureza a la que ni por asomo apeló Asturias, estos mayas posmodernos enarbolan su discurso en un mar de hibridaciones imposible de evadir. Luis de Lión se asumió como indio, no como maya. Los posmodernos no quieren ser llamados indios sino mayas, apelando a la political correctness. Sea a donde fuere que vaya a llevar este problema y esta polémica, Asturias sigue siendo un punto de referencia ineludible y su defensa constituye no una defensa de la ladinidad y su racismo, sino de la posibilidad necesaria de construir una nacionalidad, una nación y una identidad híbrida, mestiza, multicultural, en la que el derecho al ejercicio de las diferencias culturales no constituya una práctica de separatismo, como en el multiculturalismo norteamericano, sino una manera de integrar los componentes de la hibridación, que son y han sido siempre a su vez híbridos. En la realización de esta utopía latinoamericana, vigente para países como México, Guatemala, Bolivia, Ecuador, Perú y Brasil, el aporte de Asturias es imprescindible.

Asturias nunca quiso "dar voz" a los que no tienen voz ni ser él la voz por la que hablen los sin voz, como fue el caso de Neruda. Asturias incorporó lo maya a su identidad y puso lo maya en el centro de la identidad guatemalteca, poniéndo con ello a todas las culturas precolombinas que sobrevivien en América Latina en el centro de los proyectos de nación de entonces en adelante. Es una hazaña de ladino mestizo, como su testimonio es una hazaña de maya mestiza para Menchú..$^{34}$

La revaloración de Asturias no implica una sobrevaloración de la centralidad ni del canon, ni tampoco una subvaloración de la oralidad subalterna en la constitución de un sujeto nacional multicultural y mestizo, pero sí es -y quiere ser- un arma ideológica en contra de los fundamentalismos subalternos, de suyo demagógicosy que en nada ayudan a la reformulación de la utopía. Por eso su comeback resulta tan emocionante como peligroso. En todo caso, como hijo pródigo, Asturias se acerca de nuevo a su pueblo y se reafirma como lo que para Coronel Urtecho era Darío: un "paisano inevitable".

34 "Para que la voz de una cultura pueda ser 'escuchada' por otra, hay dos métodos posibles. O se necesita un autor étnico imaginario, proveniente del 'interior' de la cultura étnica, como sucede en lo que se ha dado en llamar etnoficción, o se precisa efectuar alteraciones en los modelos de comunicación de la cultura receptora" Rowe y Schelling, op.cit., 261. Sin duda, tanto Asturias como Menchú han contribuido a que los mayas y su cultura fueran escuchados por el mundo central y dominante, introduciendo alteraciones en los modelos de comunicación de la cultura receptora, uno desde una posicionalidad ladina y letrada, y la otra desde una posicionalidad maya y oral. 